\title{
Involvement in maternal care by migrants and ethnic minorities: a narrative review
}

\author{
Cláudia De Freitas ${ }^{1,2,3^{*}}$, Janka Massag ${ }^{1}$, Mariana Amorim ${ }^{1}$ and Sílvia Fraga ${ }^{1,2}$
}

\author{
* Correspondence: claudia. \\ defreitas@ispup.up.pt \\ ${ }^{1}$ EPIUnit - Instituto de Saúde \\ Pública, Universidade do Porto, Rua \\ das Taipas, 135, 4050-600 Porto, \\ Portugal \\ ${ }^{2}$ Departamento de Ciências da \\ Saúde Pública e Forenses e \\ Educação Médica, Faculdade de \\ Medicina, Universidade do Porto, \\ Porto, Portugal \\ Full list of author information is \\ available at the end of the article
}

\begin{abstract}
Background: Guidelines for improving the quality of maternal health services emphasise women's involvement in care. However, evidence about migrant and ethnic minorities' preferences for participation in maternal care remains unsystematised. Understanding these populations' experiences with and preferred forms of involvement in care provision is crucial for imbuing policies and guidelines with sensitivity to diversity and for implementing people-centred care. This paper presents a narrative synthesis of empirical studies of involvement in maternal health care by migrants and ethnic minorities based on four key dimensions: information, communication, expression of preferences and decision-making.
\end{abstract}

Methods: Studies indexed in PubMed and Scopus published until December 2019 were searched. Original quantitative, qualitative and mixed methods studies written in English and reporting on migrant and ethnic minority involvement in maternal care were included. Backward reference tracking was carried out. Three researchers conducted full-text review of selected publications.

Results: In total, 22 studies met the inclusion criteria. The majority of studies were comparative and addressed only one or two dimensions of involvement, with an emphasis on the information and communication dimensions. Compared to natives, migrants and ethnic minorities were more likely to (1) lack access to adequate information as a result of health care staff's limited time, knowledge and misconceptions about women's needs and preferences; (2) report suboptimal communication with care staff caused by language barriers and inadequate interpreting services; (3) be offered fewer opportunities to express preferences and to have preferences be taken less into account; and (4) be less involved in decisions about their care due to difficulties in understanding information, socio-cultural beliefs and previous experiences with care provision less attuned with playing an active role in decision-making and care staff detracting attitudes.

(Continued on next page)

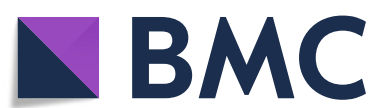

(c) The Author(s) 2020 Open Access This article is licensed under a Creative Commons Attribution 40 International License, which permits use, sharing, adaptation, distribution and reproduction in any medium or format, as long as you give appropriate credit to the original author(s) and the source, provide a link to the Creative Commons licence, and indicate if changes were made. The images or other third party material in this article are included in the article's Creative Commons licence, unless indicated otherwise in a credit line to the material. If material is not included in the article's Creative Commons licence and your intended use is not permitted by statutory regulation or exceeds the permitted use, you will need to obtain permission directly from the copyright holder. To view a copy of this licence, visit http://creativecommons.org/licenses/by/4.0/. The Creative Commons Public Domain Dedication waiver (http://creativecommons.org/publicdomain/zero/1.0/) applies to the data made available in this article, unless otherwise stated in a credit line to the data. 
(Continued from previous page)

Conclusion: Constraints to adequate and inclusive involvement in maternal care can hinder access to quality care and result in severe negative health outcomes for migrant and ethnic minority women. More research is needed into how to tailor the dimensions of involvement to migrant and ethnic minorities' needs and preferences, followed by provision of the resources necessary for effective implementation (e.g. sufficient time for consultations, optimal interpreter systems, health care staff training).

Keywords: User involvement, Patient participation, Maternal health services, Migrant, Ethnic minority

\section{Background}

The number of international migrants has been growing globally, and it is now estimated at 258 million [1]. High population mobility is unlikely to come to a halt. Millions of people are on the move driven by personal aspirations, increased opportunities for travel, but also the need to flee extreme poverty, war, persecution and the negative consequences of climate change. The rising number of people living outside their countries of origin poses a public health challenge as migrants and ethnic minorities tend to be more negatively affected by inequities in health status and access to health care than native populations [2].

Access to maternal care is reported to be worse for migrants than for natives, especially for displaced and refugee populations and those with irregular status and a low socioeconomic position [3, 4]. This is particularly problematic because pregnant women are an especially vulnerable group and limited access to needed care impends on their right to health and healthy child development [3]. Language and cultural differences, as well as institutional discrimination and structural barriers, have been reported as factors that may reduce migrant and ethnic minority women's access to maternal health services $[4,5]$. Evidence also suggests that migrant and ethnic minority women experience increased maternal mental ill-health and maternal and perinatal mortality compared to natives [6-10]. Evidence on other perinatal outcomes is mixed. While most studies have shown poorer outcomes among migrants (e.g. complicated pregnancies, low birth weight, preterm delivery, congenital malformations, abortion), some studies reported improved outcomes (e.g. pre-eclampsia, eclampsia, breastfeeding, low birth weight) and other studies have found no differences between migrant and native groups (e.g. pregnancy complications, preterm delivery) [5, 11-17].

Maternal and child health is a public health priority under the Sustainable Development Goals [18]. As a result, guidelines concerned with maternal care improvement have been published in recent years. Recommendations are often based on the premise that women want to be involved in care decision-making, and their focus is set on electing women's preferences and choices through effective communication [19]. Service user involvement has been found to improve treatment outcomes [20], patient safety [21] and care accessibility [22, 23], which are all key elements of quality care [24]. However, evidence about migrants and ethnic minorities' perceptions of involvement in maternal care is limited and unsystematic.

User involvement in health care is a multifaceted phenomenon "through which individuals formulate meanings and actions that reflect their desired degree of participation 
in individual [ ] decision-making processes" [25]. As such, it needs to be viewed as a dynamic process of co-production that is grounded in dialogue and negotiation between the parties involved (i.e. service users and care professionals) [25, 26] and which can lead to disparate outcomes regarding decision-making (from full willingness to make decisions to preferred delegation) [27]. Understanding migrants and ethnic minorities' experiences with and preferred forms of involvement is crucial for imbuing guidelines and policies with sensitivity to diversity [28-30], implementing care centred on people's needs, values and preferences [31-33] and avoiding the reproduction of inequalities through promotion of inadequate or undesired participation [34, 35]. This paper aims to synthesise existing knowledge about migrant and ethnic minority involvement in maternal care by providing a narrative review of empirical studies on this issue.

\section{Defining user involvement in health care}

User involvement in health care started gaining currency in the late 1970s [36]. Emerging as a reaction to paternalistic professionalism that restricted patients' agency over their own health and care management [37], it was rebranded as a patient choice in the 1980s, following the rise of New Public Management and its precept of cost containment through the promotion of patients' autonomy and responsibilisation (e.g. adoption of healthy lifestyles) [38]. Towards the end of the twentieth century, user involvement regained its original dialogic aura under the philosophy of people-centred care [39]. At present, it is a core dimension in guidelines for care quality improvement, not least in the field of maternal care $[40,41]$ where access to quality care is promoted as a right [4].

Despite increasing recognition and practice, there is no consensual definition of user involvement. Terms such as "involvement", "participation" and "engagement" are used interchangeably, though not always with the same meaning [26, 42, 43]. Definitions of user involvement tend to differ on the emphasis given to decision-making and to the roles awarded to the actors involved, i.e. service users and health professionals. Some authors focus on the dialogic relationship underlining user involvement. They assert the need for four basic elements to be present for involvement to unfold: (a) a respectful relationship between health professionals and service users, (b) commitment to reduce the knowledge gap between the parties involved through the provision of adequate information, (c) devolution of power to service users by health professionals and (d) opportunity for involvement in treatment decision-making by users to the extent they see fit $[37,44-46]$. Other authors emphasise the act of decision-making and health professionals' leading role in involving service users by providing information, clarifying doubts, actively inviting users to participate and taking their opinions and wishes into account [47-49].

The centrality of decision-making on the process of user involvement has been criticised on several accounts. Studies show that even when service users are unwilling to participate in decision-making, they still value being involved, namely by receiving information from health professionals and having them take their preferences into account $[27,50]$. Research further shows that service users want to be involved in decision-making to different degrees [51-53] and that, when involved at the preferred level, they experience positive health outcomes as a result [54]. Understanding what 
involvement means for service users, and the subjective feelings it invokes on both users and professionals, has thus been advocated as a key stepping stone in attempts geared towards its definition [55].

Andrew Thompson (2007) studied lay people's views of and preferences for involvement in health care following a deliberative design that included a group of participants differing in age, gender, ethnicity, social class, health needs and experiences with the health care system. According to the study participants, involvement entailed one or more of the following attributes: information, explanation, openness, communication, shared knowledge, emotional care, exploration of choices, dialogue and decisionmaking. Based on the most frequently mentioned attributes, Thompson proposes an empirically grounded definition of user involvement that entails a range of steps where participation in decision-making is presented as an opportunity, rather than an obligation. User involvement can thus be "broadly understood as involving patients in discussion about their condition, providing them with relevant information, asking for their opinion on possible treatments, and involving them in the decision-making process, should they so wish" [56]. This definition highlights four core dimensions of involvement: information, communication, expression of preferences and decision-making. These dimensions are used to organise our review of migrant and ethnic minority involvement in maternal care.

\section{Methodology}

A narrative review was conducted to identify empirical research about migrant and ethnic minority involvement in maternal care. Relevant references were retrieved by searching the electronic databases PubMed and Scopus in December 2019. The search expression combined sets of terms relating to user involvement (involvement, participation, engagement), maternal care (maternal, reproductive, perinatal, antenatal) and migrant and minority populations (migrant, immigrant, ethnic minority, asylum seeker, refugee). Only original full-length empirical studies written in English were considered (reviews, editorials and commentaries were excluded). All relevant quantitative, qualitative and mixed methods studies reporting data on involvement in maternal care by migrant and ethnic minorities were included, independently of addressing only one or more of the four dimensions of involvement described earlier. Backward reference tracking of the articles included was also carried out.

In total, 91 references were generated and 22 publications met the inclusion criteria. Full-text review of selected publications was independently conducted by three researchers. Data extraction from each publication was carried out and tabulated (Table 1). The main themes for analysis were deductively drawn from Thompson's definition of user involvement [56] selected for the purposes of this review, and categories were established inductively through analysis of the publications.

\section{Migrant and ethnic minority involvement in maternal care}

Empirical evidence about involvement in maternal care by migrants and ethnic minorities is scarce, particularly regarding the expression of preferences and participation in decision-making. The majority of the studies reviewed addressed only one or two dimensions of involvement $(n=17)$, with a higher number of studies focusing on 


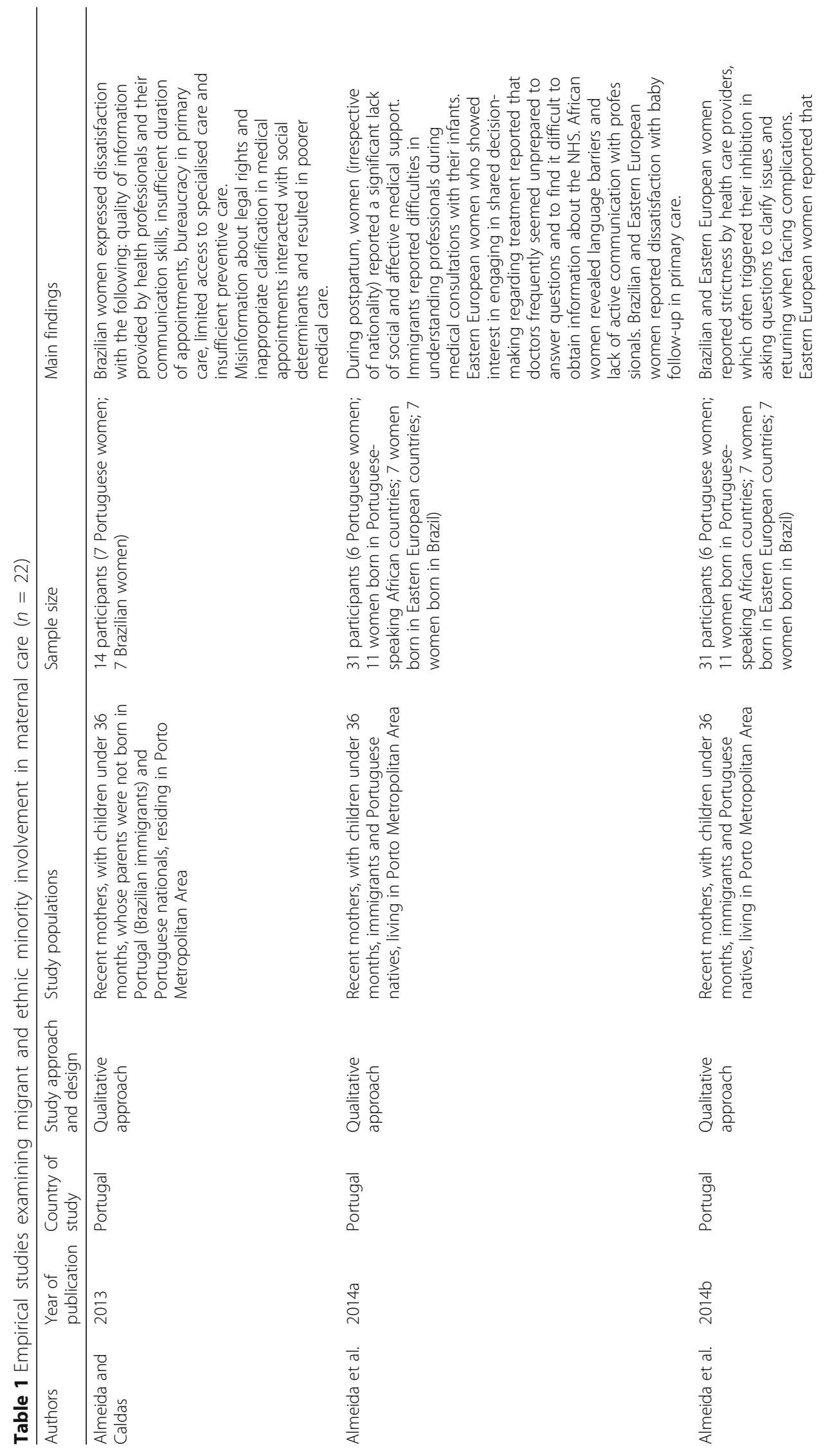




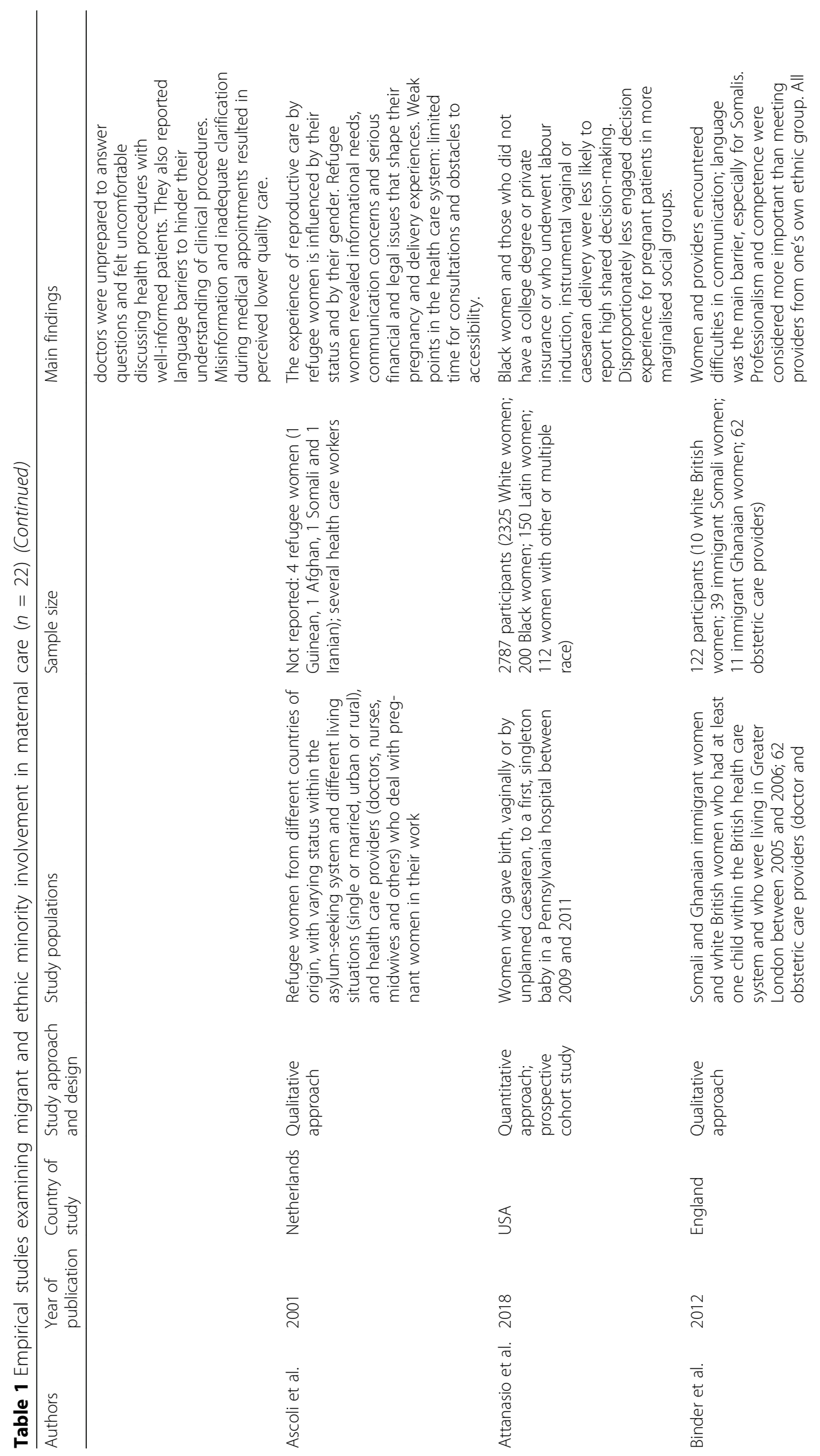




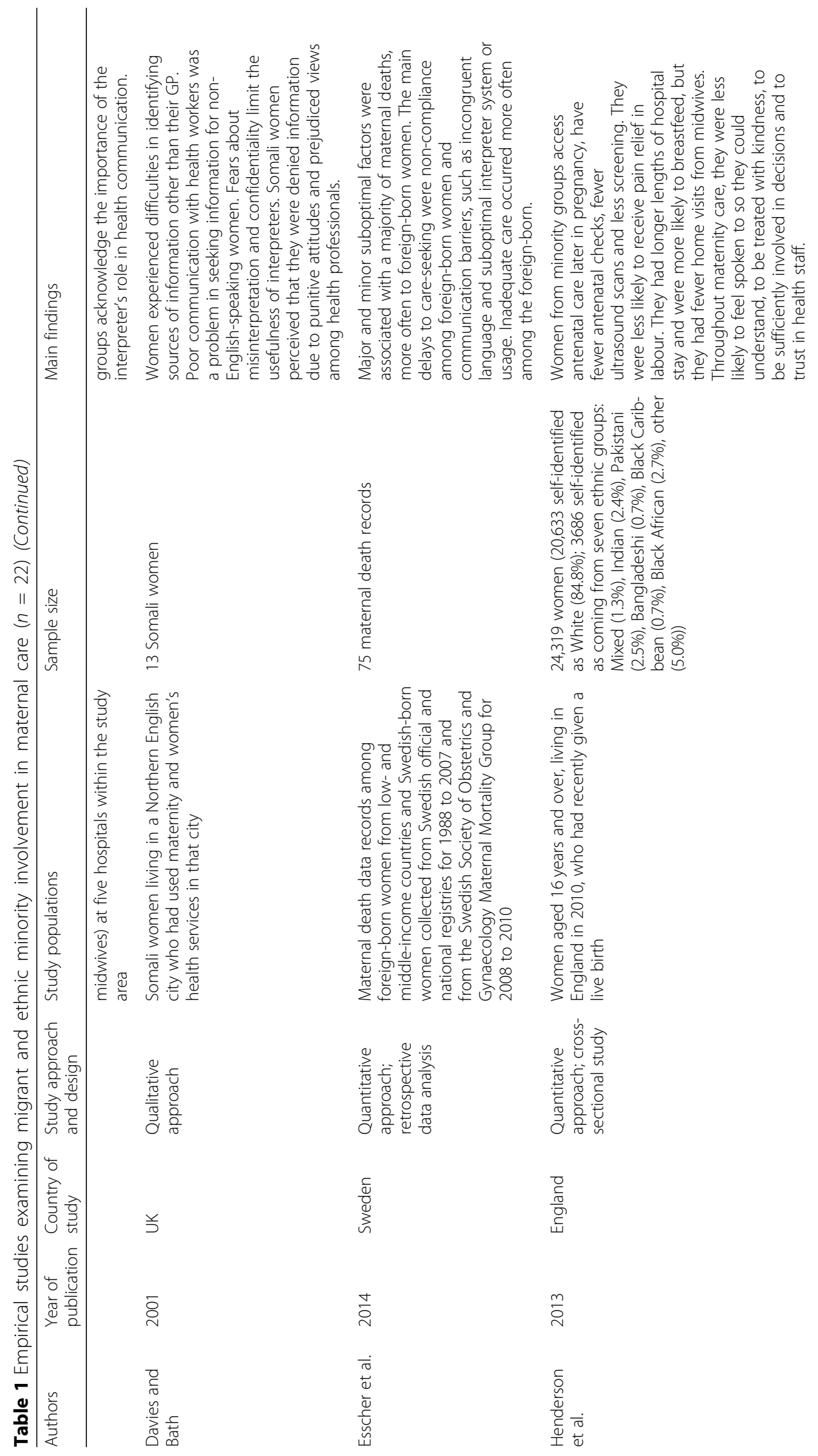




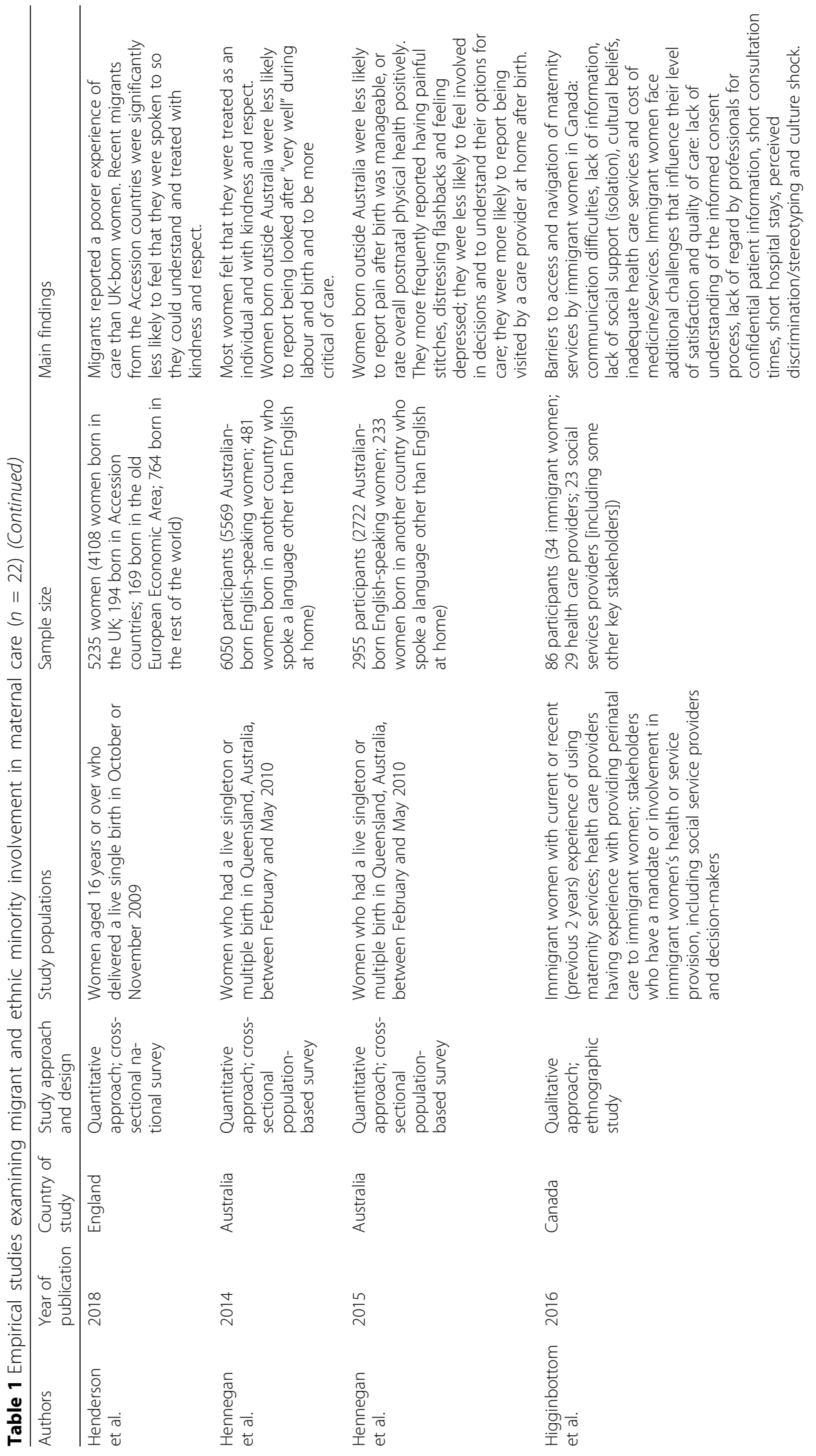




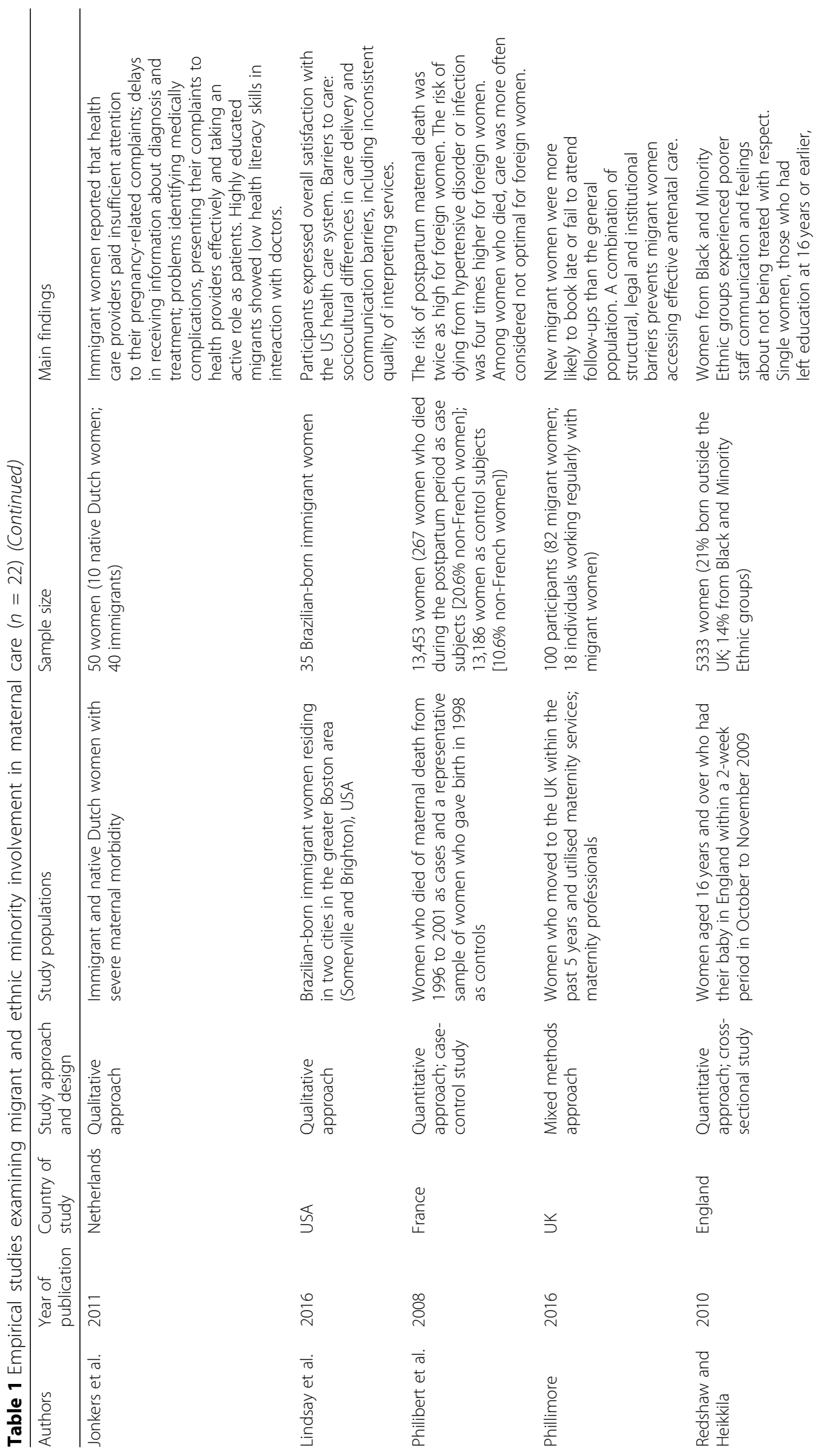




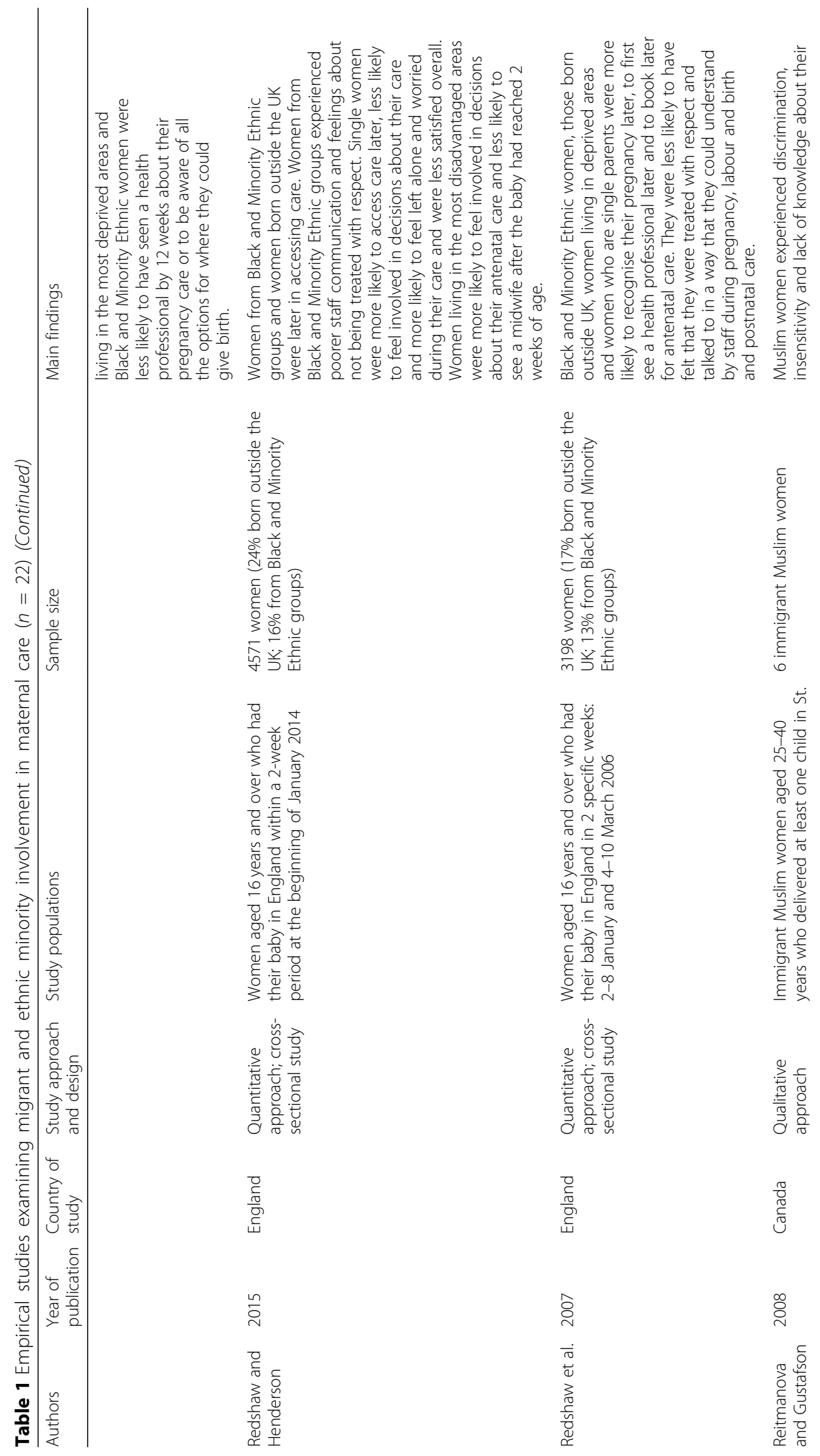




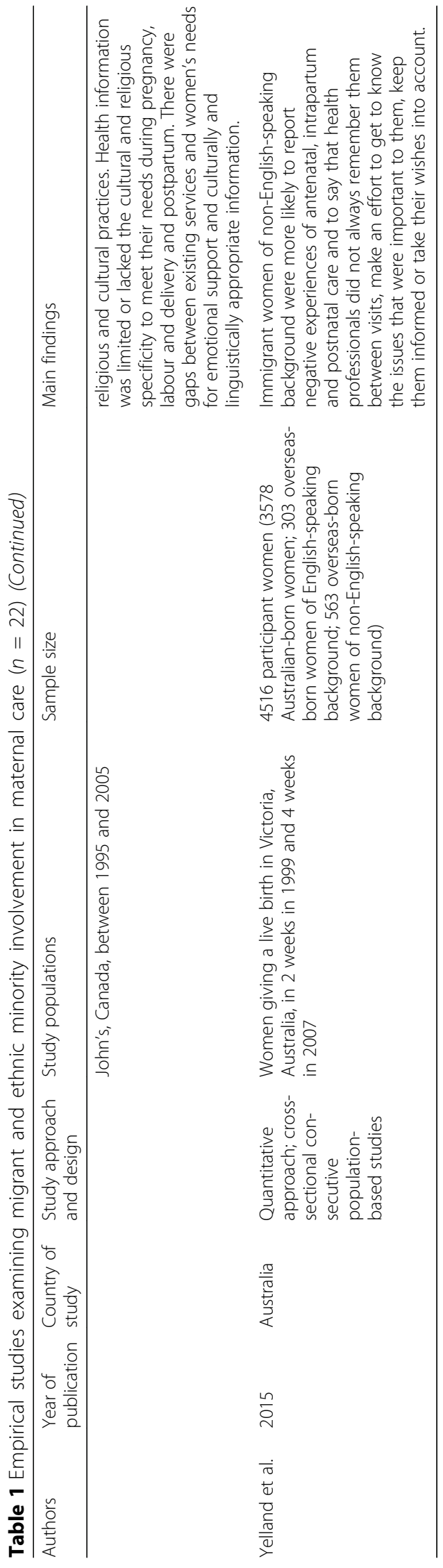


information and communication. Five studies approached three dimensions of involvement [57-61], and none addressed all of them.

Evidence derives mainly from studies conducted in the UK $(n=8)$, Australia $(n=3)$ and Portugal $(n=3)$ and published between 2001 [62, 63] and 2018 [64, 65], with an increase of research in recent years. A total of 14 out of the 22 studies reviewed were published between 2013 and 2018. An almost even number of studies adopted a quantitative approach $(n=11)$ and a qualitative approach $(n=10)$, with only one study employing a mixed methods approach. Most quantitative studies used a cross-sectional design $(n=9)$ and compared between native and migrant and ethnic minority populations $(n=11)$, but samples of the latter group were small (ranging between 8\% [66, 67] and 24\% [57]). The qualitative studies explored the perspectives of migrant and ethnic minority women, with four comparing between natives and migrants and three including other stakeholders (e.g. health care workers, social services providers). The mixed methods study [68] relied on questionnaires and in-depth interviews with migrant women and maternity professionals.

\section{Information}

Access to adequate information about maternal care is not equally distributed among native and migrant and ethnic minority service users. Two population-based studies carried out in England show that Black and Minority Ethnic women born in and outside the United Kingdom (UK) were provided less information than White UK-born women [57, 61, 69]. Another population-based study on maternal care done in Australia showed that migrant women were less likely to understand the staff [58, 67] and to be kept informed during labour and birth [58] when compared to native Australian women.

Although migrants and ethnic minorities may require tailor-made information to navigate maternal care services, their informational needs are often disregarded by health professionals who either show indifference [70] or assume they have sufficient knowledge $[63,68]$ and use medical jargon that can increase their difficulties in understanding and realising such basic rights as informed consent [60]. This is further exacerbated by the lack of information provision regarding labour as reported by Muslim migrant women in Australia [71] and non-English-speaking Somali women in the UK [62]. The latter perceived racially prejudiced views espoused by health professionals as the main reason for not receiving enough information [62]. Health professionals' limited time, knowledge and support to develop an understanding of the difficulties experienced by migrant women may lead to the reification of misconceptions about their behaviour (e.g. explaining failed appointments with migrant women's undervaluing of antenatal care), which in turn may hinder the quality of clinical interactions and information sharing [68].

\section{Communication}

Communication problems are more frequently reported by migrant and ethnic minority women when compared to natives and result in more severe consequences for the former groups. Two population-based studies carried out in England found Black and Minority Ethnic women to be less likely to be spoken to in a way that they could 
understand [59] and to rate communication with maternal care staff worse than native women [61]. Suboptimal communication was also more often reported by migrant women than by non-migrant women in studies undertaken in France, Sweden and England $[64,72,73]$.

Limited command of the host country's language impacts communication negatively. A study from the UK found that non-English-speaking Somali women experienced poorer communication with health professionals when compared to English-speaking Somalis [62]. Immigrant women with low proficiency in the host country's language living in Canada, the USA, England and Portugal also experienced barriers in communication, which limited their access to maternal care services [60, 71, 74-77].

Although language barriers may be overcome through the use of interpreters, resource shortage often leads to reliance on family members, friends or children as interpreters. Suboptimal interpreter system or usage was found to be problematic and disempowering for migrant women. It caused women to be excluded from decisions regarding their pregnancies-undertaken instead by other family members [68], to fear misinterpretation and breaches in patient confidentiality [62] and to be exposed to adverse obstetric outcomes [63,73]. Resorting to children as interpreters may also cause them extreme discomfort when they have to translate and convey bad news [74].

Poor communication was found to be associated with mortality and severe maternal morbidity among migrant women. In Sweden, suboptimal care was found to be a factor for maternal death more frequently among foreign-born women than among natives. Many of the deaths of foreign-born women were associated with communicationrelated barriers and delayed health care seeking (e.g. inability to access services was caused mainly by language barriers and substandard interpretation services) [73]. In the Netherlands, care providers not listening to service users and users not being able to play an active role in consultations were reported as factors for disease development among migrants but not among natives [78].

\section{Expression of preferences}

Migrant and ethnic minority women's preferences may be shaped by perspectives of and expectations from maternal care provision that differ from those prevailing in host countries. Those preferences may not be accommodated by local health care systems. A study carried out in the USA found that Brazilian women prefer to have access to labour ward admission and pain management procedures earlier than they are typically offered by local maternity care [77]. Inability to exercise those preferences caused Brazilian immigrants to perceive delayed admission during labour and delayed use of anaesthetics, which impacted negatively on their satisfaction with the care received [77].

Some migrant and ethnic minority groups may also be offered less opportunities to express their preferences and to see their preferences be less taken into account. A study done in the UK found that Pakistani and Black African women experienced less choice regarding the place of birth and felt significantly less likely to be able to move around during labour when compared to White, Mixed, Indian and Black Caribbean women [59]. The same study also found that Pakistani and Bangladeshi women were less likely than the other groups to feel their partners were made welcome. Two studies done in England found that Black and Minority Ethnic women born outside the UK 
were less aware of all options for the place of birth than UK-born White women [57, 61]. Another population-based study conducted in Australia found that immigrant women were less likely to report that care providers explained options regarding labour management than Australian-born women [58].

\section{Decision-making}

Involvement in decision-making regarding maternal care appears to be influenced by migrant and ethnic minority women's socio-cultural background and beliefs about and previous experiences with care provision, difficulties in accessing information and expressing preferences, health care professionals' attitudes towards involvement and use of obstetric procedures. While some migrant groups are more acquainted with paternalistic doctor-patient relationships and expect health professionals to make decisions without involving them $[74,75]$, others lack the language skills to understand available options and to take part in decision-making [60, 74]. However, involvement in decision-making may also be detracted by health care professionals. A study carried out in Portugal found that although Eastern European immigrants wanted to take part in care decision-making, they felt their intents were abridged by doctors who seemed uncomfortable in answering their questions and in providing information or discussing clinical procedures with them $[75,76]$.

Several studies show that migrant and ethnic minority women tend to participate less in maternal care decision-making when compared to native women. Two studies carried out in England found that ethnic minority groups were less likely to report being sufficiently involved in decisions regarding antenatal care [57,59] and during labour and birth [59] than White women. In part, this appears to be explained by limited awareness of opportunities for participation. A population-based survey done in Australia found that women born outside Australia who spoke a language other than English at home were less likely to know that they could be involved in decisions about themselves and their babies, when compared to Australian-born English-speaking women [66]. They were also less likely to be informed about all options when in need of making a decision [66].

Findings regarding respect for women's preferences once they get involved in decision-making are inconsistent. A population survey carried out in Australia in 2008 showed that immigrant women of non-English-speaking background were more likely than native women to report that intrapartum care staff did not take their wishes into account [58]. However, another population-based survey carried out 2 years later in the same country found no differences in regard to staff's respect for decisions made during labour by women born outside Australia who spoke a language other than English at home and Australian-born English-speaking women [67]. And yet another study conducted in the USA found that women reporting lower levels of shared decision-making during birth were disproportionately likely to be from ethnic minority groups, to be less educated and to lack health insurance [65]. The same study also found that obstetric procedures such as labour induction, assisted vaginal delivery and caesarean delivery were all associated with lower perceived involvement and that Black women who delivered by caesarean reported considerably lower levels of shared decision-making compared to White women [65]. 


\section{Conclusion}

The majority of the comparative studies reviewed showed that migrants and ethnic minorities report lower levels of involvement than natives in all four core dimensions of involvement. Migrants and ethnic minorities were more likely to (1) lack access to adequate information as a result of health care staff's limited time, knowledge and misconceptions about women's needs and preferences; (2) report suboptimal communication with care staff caused by language barriers and inadequate interpreting services; (3) be offered fewer opportunities to express preferences and to have preferences be taken less into account; and (4) be less involved in decisions about their care due to difficulties in understanding information, socio-cultural beliefs and previous experiences with care provision less attuned with playing an active role in decisionmaking and care staff detracting attitudes.

Constraints to adequate and inclusive involvement in maternal care can hinder access to quality care and result in severe negative health outcomes for migrant and ethnic minority women and their offspring $[73,78]$. Acting to improve their involvement in maternal care demands a multi-level approach. On the one hand, more research is needed into how to tailor the various dimensions of involvement to migrant and ethnic minorities' needs and preferences. Further inquiry into health care staff's beliefs, expectations and attitudes towards involvement is also needed, including how these may be influenced not only by (lack of) cultural competence but also by factors such as migrants' origin, status and duration of stay in the host country $[75,79]$. On the other hand, it is necessary to make resources available for effective implementation. This includes devising diversity sensitive information materials aimed at increasing women's awareness of opportunities for involvement, allocating sufficient time for consultations, making optimal interpreter services accessible and training care staff to attend to the involvement needs and preferences of increasingly diverse service users. Finally, health advocacy is required to challenge systemic barriers, reduce implementation gaps and ensure that policy finds its way into practices that respect every person's reproductive rights $[29,80,81]$. This will entail acting beyond the health sector to change discriminatory social norms and gender biases, develop inclusive policies and enforce new laws to uphold human rights. Partnerships involving multiple stakeholders working from across sectors, and at local, national and international governance levels, are key to promoting sustainable social and policy transformation $[4,82]$.

Acknowledgements

We are grateful to the reviewers for their valuable comments and suggestions.

\section{Authors' contributions}

CF, JM and SF conceived and designed the study. CF, JM and MA undertook the review of empirical studies and wrote the first draft. SF reviewed the draft, and all authors contributed to the final manuscript. The authors read and approved the final manuscript.

Funding

This study was funded by national funding from the Foundation for Science and Technology - FCT (Portuguese Ministry of Science, Technology and Higher Education) under the Unidade de Investigação em Epidemiologia Instituto de Saúde Pública da Universidade do Porto (EPIUnit) (POCl-01-0145-FEDER-006862; Ref. UID/DTP/04750/2019), the DL57/2016/CP1336/CT0001 (CF), and CEECIND/01516/2017/CP1406/CT0001 (SF).

Availability of data and materials

All data generated or analysed for the purposes of the study presented are included in this article. 


\section{Consent for publication}

Not applicable

\section{Competing interests}

The authors declare that they have no competing interests.

\section{Author details}

'EPIUnit - Instituto de Saúde Pública, Universidade do Porto, Rua das Taipas, 135, 4050-600 Porto, Portugal.

${ }^{2}$ Departamento de Ciências da Saúde Pública e Forenses e Educação Médica, Faculdade de Medicina, Universidade do Porto, Porto, Portugal. ${ }^{3}$ Centre for Research and Studies in Sociology, University Institute of Lisbon (ISCTE-IUL), Lisbon, Portugal.

Received: 30 January 2020 Accepted: 16 March 2020

Published online: 07 April 2020

\section{References}

1. IOM. Migration data portal. The bigger picture. 2019.

2. Bradby $H$, Humphris $R$, Newall D, Phillimore J. Public health aspects of migrant health: a review of the evidence on health status for refugees and asylum seekers in the European Region. Health Evi ed. WHO Regional Office for Europe: Copenhagen; 2015.

3. Women Political Leaders Global Forum. Improving maternal healthcare for vulnerable women in EU28: what can you do? 2018.

4. Starrs AM, Ezeh AC, Barker G, Basu A, Bertrand JT, Blum R, et al. Accelerate progress - sexual and reproductive health and rights for all: report of the Guttmacher-Lancet Commission. Lancet. 2018;391(10140):2642-92.

5. Keygnaert I, Ivanova O, Guieu A, Van Parys A-S, Leye E, Roelens K. What is the evidence on the reduction of inequalities in accessibility and quality of maternal health care delivery for migrants? A review of the existing evidence in the WHO European Region. WHO Regional Office for Europe: Copenhagen; 2016.

6. Hayes I, Enohumah K, McCaul C. Care of the migrant obstetric population. Int J Obstet Anesth. 2011;20(4):321-9.

7. Almeida LM, Caldas J, Ayres-De-Campos D, Salcedo-Barrientos D, Dias SF. Maternal healthcare in migrants: a systematic review. Matern Child Health J. 2013;17(8):1346-54.

8. Van Den Akker T, Van Roosmalen J. Maternal mortality and severe morbidity in a migration perspective. Best Pract Res Clin Obstet Gynaecol. 2016;32:26-38

9. Pedersen GS, Grøntved A, Mortensen LH, Andersen AMN, Rich-Edwards J. Maternal mortality among migrants in Western Europe: a meta-analysis. Matern Child Health J. 2014;18(7):1628-38.

10. Almeida LM, Santos CC, Caldas JP, Ayres-De-Campos D, Dias SF. Obstetric care in a migrant population with free access to health care. Int J Gynecol Obstet. 2014;126(3):244-7.

11. Lewis $\mathrm{G}$. The confidential enquiry into maternal and child health (CEMACH). Saving mothers' lives: reviewing maternal death to make motherhood safer - 2003-2005. The seventh report on confidential enquiries into maternal deaths in the United Kingdom. London: CEMACH; 2007.

12. Teixeira C, Correira S, Victora CG, Barros H. The Brazilian preference: cesarean delivery among immigrants in Portugal. PLOS ONE. 2013;8(3):24-7.

13. Urquia ML, Glazier RH, Gagnon AJ, Mortensen LH, Nybo Andersen AM, Janevic T, et al. Disparities in pre-eclampsia and eclampsia among immigrant women giving birth in six industrialised countries. BJOG. 2014;121(12):1492-500.

14. Heslehurst N, Brown H, Pemu A, Coleman H, Rankin J. Perinatal health outcomes and care among asylum seekers and refugees: a systematic review of systematic reviews. BMC Med. 2018;16(1):1-25.

15. Bollini P, Pampallona S, Wanner P, Kupelnick B. Pregnancy outcome of migrant women and integration policy: a systematic review of the international literature. Soc Sci Med. 2009;68(3):452-61.

16. Kana MA, Rodrigues C, Fonseca MJ, Santos AC, Barros H. Effect of maternal country of birth on breastfeeding practices: results from Portuquese GXXI birth cohort. Int Breastfeed J. 2018;13:15.

17. Lisi C, De Freitas C, Barros H. Maternal country of birth and in-hospital exclusive breastfeeding: results from a Portuguese study. Eur J Public Health. 2019;29(Suppl 4):408.

18. UN. Sustainable development goals 2030. 2016

19. WHO. Intrapartum care for a positive childbirth experience. Geneva: World Health Organization; 2018

20. Loh A, Leonhart R, Wills CE, Simon D, Härter M. The impact of patient participation on adherence and clinical outcome in primary care of depression. Patient Educ Couns. 2007;65:69-78.

21. Coulter A, Ellins J. Effectiveness of strategies for informing, educating, and involving patients. BMJ. 2007:335:24-7.

22. Crawford MJ, Rutter D, Manley C, Weaver T, Bhui K, Fulop N, et al. Systematic review of involving patients in the planning and development of health care. BMJ. 2002;325:1263.

23. Omeni E, Barnes M, MacDonald D, Crawford M, Rose D. Service user involvement: impact and participation: a survey of service user and staff perspectives. BMC Health Serv Res. 2014;14:491.

24. Tunçalp Ö, Were WM, MacLennan C, Oladapo OT, Gülmezoglu AM, Bahl R, et al. Quality of care for pregnant women and newborns-the WHO vision. BJOG. 2015:122(8):1045-9.

25. Tritter JQ, McCallum A. The snakes and ladders of user involvement: moving beyond Arnstein. Health Policy. 2006;76(2): $156-68$.

26. Higgins T, Larson E, Schnall R. Unraveling the meaning of patient engagement: a concept analysis. Patient Educ Couns, 2017;100(1):30-36.

27. Fredriksson M, Eriksson M, Tritter J. Who wants to be involved in health care decisions? Comparing preferences for individual and collective involvement in England and Sweden. BMC Public Health. 2018;18:18.

28. Mladovsky P, Rechel B, Ingleby D, McKee M. Responding to diversity: an exploratory study of migrant health policies in Europe. Health Policy. 2012;105:1-9. 
29. De Freitas C, García-Ramirez M, Aambø A, Buttigieg SC. Transforming health policies through migrant user involvement: lessons learnt from three European countries. Psychosocial Intervention. 2014;23(2):105-13.

30. Escobar-Ballesta M, García-Ramírez M, De Freitas C. Taking stock of Roma health policies in Spain: lessons for health governance. Health Policy. 2018;122(4):444-51.

31. WHO. Quality of care: a process for making strategic choices in health systems. Geneva: World Health Organization; 2006.

32. De Freitas C. Aiming for inclusion: a case study of motivations for involvement in mental health-care governance by ethnic minority users. Health Expect. 2015;18(5):1093-104.

33. Montesanti SR, Abelson J, Lavis JN, Dunn JR. Enabling the participation of marginalized populations: case studies from a health service organization in Ontario. Canada. Health Promot Int. 2017;32:636-49.

34. Johnson M. User and community involvement in health and social care research with migrants and ethnic minorities. In: Chiarenza A, Deville W, Kotsioni I, editors. Ingleby D. Garant Uitgevers: Apeldoorn; 2012.

35. De Freitas C, Martin G. Inclusive public participation in health: policy, practice and theoretical contributions to promote the involvement of marginalised groups in healthcare. Soc Sci Med. 2015;135:31-9.

36. De Freitas C. Public and patient participation in health policy, care and research. Porto Biomed J. 2017;2(2):31-2.

37. Cahill J. Patient participation: a concept analysis. J Adv Nurs. 1996;24(3):561-71.

38. Dent M, Pahor M. Patient involvement in Europe - a comparative framework. J Health Organ Manag. 2015;29(5):546-55.

39. Pulvirenti M, Hons BA, McMillan J, Hons BA. Empowerment, patient centred care and self-management. Health Expect. 2011;17:303-10.

40. WHO. WHO recommendations on health promotion interventions for maternal and newborn health. Geneva: WHO; 2015.

41. WHO. Improving the health care of pregnant refugee and migrant women and newborn children. (Technical guidance on refugee and migrant health). Copenhagen: WHO Regional Office for Europe; 2018.

42. Vahdat S, Hamzehgardeshi L, Hessam S, Hamzehgardeshi Z. Patient involvement in health care decision making: a review. Iran Red Cres Med J. 2014;16(1):e12454.

43. Kvæl LAH, Debesay J, Langaas A, Bye A, Bergland A. A concept analysis of patient participation in intermediate care. Patient Educ Couns. 2018;101(8):1337-50.

44. Eldh AC. Patient participation - what is it and what is it not. Örebro: Universitetbiblioteket; 2006.

45. Sahlsten MJM, Larsson IE, Plos KAE. An analysis of the concept of patient participation. Nursing Forum. 2008;43(1):2-11.

46. Castro EM, Van Regenmortel T, Vanhaecht K, Sermeus W, Van Hecke A. Patient empowerment, patient participation and patient-centeredness in hospital care: a concept analysis based on a literature review. Patient Educ Couns. 2016;99: 1923-39.

47. Wensing M, Wetzels R, Hermsen J, Baker R. Do elderly patients feel more enabled if they had been actively involved in primary care consultations? Patient Educ Couns. 2007;68(3):265-9.

48. Epstein RM, Street RL. The values and value of patient-centered care. Ann Fam Med. 2011;9(2):100-3.

49. Tambuyzer E, Van Audenhove C. Is perceived patient involvement in mental health care associated with satisfaction and empowerment? Health Expect. 2015;18(4):516-26.

50. Lerman CE, Brody DS, Caputo GC, Smith DG, Lazaro CG, Wolfson HG. Patients' perceived involvement in care scale. J Gen Intern Med. 1990;5(1):29-33.

51. Say R, Murtagh M, Thomson R. Patients' preference for involvement in medical decision making: a narrative review. Patient Educ Couns. 2006;60(2):102-14.

52. Brom L, Pasman HRW, Widdershoven GAM, Van Der Vorst MJDL, Reijneveld JC, Postma TJ, et al. Patients' preferences for participation in treatment decision-making at the end of life: qualitative interviews with advanced cancer patients. PLoS ONE. 2014;9(6):e100435.

53. Brabers AEM, Rademakers JJDJM, Groenewegen PP, van Dijk L, de Jong JD. What role does health literacy play in patients' involvement in medical decision-making? PloS ONE. 2017;12(3):e0173316.

54. Vogel BA, Leonhart R, Helmes AW. Communication matters: the impact of communication and participation in decision making on breast cancer patients' depression and quality of life. Patient Educ Couns. 2009;77(3):391-7.

55. Entwistle VA, Watt IS. Patient involvement in treatment decision-making: the case for a broader conceptual framework. Patient Educ Couns. 2006;63(3):268-78.

56. Thompson AGH. The meaning of patient involvement and participation in health care consultations: a taxonomy. Soc Sci Med. 2007;64:1297-310.

57. Redshaw M, Henderson J. Safely delivered: a national survey of women's experiences of maternity care 2014. Oxford: National Perinatal Epidimiology Unit; 2015.

58. Yelland J, Riggs E, Small R, Brown S. Maternity services are not meeting the needs of immigrant women of non-English speaking background: results of two consecutive Australian population based studies. Midwifery. 2015;31(7):664-70.

59. Henderson J, Gao H, Redshaw M. Experiencing maternity care: the care received and perceptions of women from different ethnic groups. BMC Pregnancy Childbirth. 2013;13(1):196-201.

60. Higginbottom G, Safipour J, Yohani S, O'Brien B, Mumtaz Z, Paton P, et al. An ethnographic investigation of the maternity healthcare experience of immigrants in rural and urban Alberta. Canada. BMC Pregnancy Childbirth. 2016; 16(1):1-15

61. Redshaw M, Heikkila K. Delivered with care: a national survey of women's experience of maternity care 2010. Oxford: National Perinatal Epidimiology Unit; 2010.

62. Davies M, Bath P. The maternity information concerns of Somali women in the United Kingdom. J Adv Nurs. 2001;36(2): $237-45$.

63. Ascoly N, Van Halsema I, Keysers L. Refugee women, pregnancy, and reproductive health care in the Netherlands. J Refug Stud. 2001;14(4):371-93.

64. Henderson J, Carson C, Jayaweera H, Alderdice F, Redshaw M. Recency of migration, region of origin and women's experience of maternity care in England: evidence from a large cross-sectional survey. Midwifery. 2018;67:87-94.

65. Attanasio LB, Kozhimannil KB, Kristen H. Factors influencing women's perceptions of shared decision making during labor and delivery: results from a large-scale cohort study of first childbirth. Patient Educ Couns. 2018;101(6):1130-6. 
66. Hennegan J, Redshaw M, Kruske S. Another country, another language and a new baby: a quantitative study of the postnatal experiences of migrant women in Australia. Women Birth. 2015;28(4):e124-e33.

67. Hennegan J, Redshaw M, Miller Y. Born in another country: Women's experience of labour and birth in Queensland. Australia. Women Birth. 2014;27(2):91-7.

68. Phillimore J. Migrant maternity in an era of superdiversity: new migrants' access to, and experience of, antenatal care in the West Midlands, UK. Soc Sci Med. 2016;148:152-159.

69. Redshaw M, Rowe RE, Hockley C, Brocklehurst P. Recorded delivery: a national survey of women's experience of maternity care. Oxford: National Perinatal Epidimiology Unit; 2007.

70. Almeida L, Caldas J. Migration and maternal health: experiences of Brazilian women in Portugal. Rev Bras Saúde Matern Infant. 2013;13(4):309-16.

71. Reitmanova S, Gustafson DL. "They can't understand it": maternity health and care needs of immigrant Muslim women in St. John's, Newfoundland. Matern Child Health J. 2008;12(1):101-11.

72. Philibert M, Deneux-Tharaux C, Bouvier-Colle MH. Can excess maternal mortality among women of foreign nationality be explained by suboptimal obstetric care? BJOG. 2008;115(11):1411-8.

73. Esscher A, Binder-Finnema P, Bødker B, Högberg U, Mulic-Lutvica A, Essén B. Suboptimal care and maternal mortality among foreign-born women in Sweden: maternal death audit with application of the 'migration three delays' model. BMC Pregnancy Childbirth. 2014;14(1):1-11.

74. Binder P, Borné Y, Johnsdotter S, Essén B. Shared language is essential: communication in a multiethnic obstetric care setting. J Health Commun. 2012;17(10):1171-86.

75. Almeida LM, Caldas JP, Ayres-de-Campos D, Dias SF. Assessing maternal healthcare inequities among migrants: a qualitative study. Cad Saude Publica. 2014;30(2):333-40.

76. Almeida LM, Casanova C, Caldas J, Ayres-De-Campos D, Dias SF. Migrant women's perceptions of healthcare during pregnancy and early motherhood: addressing the social determinants of health. J Immigr Minor Health. 2014;16(4):71923.

77. Lindsay AC, Oliveira MGD, Wallington SF, Greaney ML, Maria M, Machado T, et al. Access and utilization of healthcare services in Massachusetts, United States: a qualitative study of the perspectives and experiences of Brazilian-born immigrant women. BMC Health Serv Res. 2016;16:467-75.

78. Jonkers M, Richters A, Zwart J, Öry F, van Roosmalen J. Severe maternal morbidity among immigrant women in the Netherlands: patients' perspectives. Reproductive Health Matters. 2011;19(37):144-53.

79. Garrido R, Garcia-Ramirez M, Balcazar FE. Moving towards community cultural competence. Int J Intercult Relat. 2019;73: 89-101.

80. Miranda DE, Garcia-Ramirez M, Balcazar FE, Suarez-Balcazar Y. A community-based participatory action research for Roma health justice in a deprived district in Spain. Int J Environ Res Public Health. 2019;16(19):3722.

81. Wallerstein N, Duran B. Community-based participatory research contributions to intervention research: the intersection of science and practice to improve health equity. Am J Public Health. 2010;100(Suppl 1):S40-6.

82. O'Mara-Eves A, Brunton G, McDaid D, Oliver S, Kavanagh J, Jamal F, et al. Community engagement to reduce inequalities in health: a systematic review, meta-analysis and economic analysis. Public Health Res. 2013;(1)4.

\section{Publisher's Note}

Springer Nature remains neutral with regard to jurisdictional claims in published maps and institutional affiliations.

\section{Ready to submit your research? Choose BMC and benefit from}

- fast, convenient online submission

- thorough peer review by experienced researchers in your field

- rapid publication on acceptance

- support for research data, including large and complex data types

- gold Open Access which fosters wider collaboration and increased citations

- maximum visibility for your research: over 100M website views per year

At $\mathrm{BMC}$, research is always in progress.

Learn more biomedcentral.com/submissions 